\title{
Microstructural Analysis of Carbon Nanomaterials Produced from Pyrolysis/Combustion of Styrene-Butadiene-Rubber (SBR)
}

\author{
Joner Oliveira Alves ${ }^{\mathrm{a}, \mathrm{b}}$, Chuanwei Zhuo ${ }^{\mathrm{a}}$,Yiannis Angelo Levendis ${ }^{\mathrm{a}}$,Jorge Alberto Soares Tenório \\ a Department of Mechanical and Industrial Engineering, College of Engineering, \\ Northeastern University, 360 Huntington Av., Boston, MA, 02115, USA \\ ${ }^{\mathrm{b}}$ Research Centre, Aperam South America, 09, Praça $1^{\circ}$ de Maio, Centro, \\ CEP 35180-018, Timóteo, MG, Brazil \\ ${ }^{\mathrm{c}}$ Department of Metallurgical and Materials Engineering, Polytechnic School, \\ University of Sao Paulo - USP, 2463, Prof. Mello Moraes Av., \\ CEP 05508-030, São Paulo, SP, Brazil
}

Received: March 10, 2011; Revised: August 15, 2011

\begin{abstract}
Styrene-Butadiene-Rubber (SBR) is a synthetic rubber copolymer used to fabricate several products. This study aims to demonstrate the use of SBR as feedstock for carbon nanomaterials (nanofibers and nanotubes) growth, and therefore to establish a novel process for destination of waste products containing SBR. A three stage electrically heated flow reactor was used. Small pellets of rubber were pyrolyzed at a temperature of $1000{ }^{\circ} \mathrm{C}$. The pyrolyzates were mixed with oxygen-containing gases and were burned. The products of combustion were used to synthesize the carbon nanomaterials (CNMs) at the presence of a catalyst. CNMs have a wide range of potential applications due to their extraordinary mechanical, thermal and electrical properties. Produced materials were characterized by SEM and TEM, whereas combustion products were assessed using GC. Results showed that CNMs with outer diameters of 30-100 nm and lengths of about $30 \mu \mathrm{m}$ were formed. Therefore, it was demonstrated that waste products containing SBR can be used to generate CNMs which are value-added products of intense technological interest.
\end{abstract}

Keywords: nanomaterials, SBR, catalysis, combustion

\section{Introduction}

Styrene-Butadiene-Rubber (SBR) is a synthetic rubber copolymer consisting of styrene and butadiene. This material is used in a number of different applications around the world, such as shoe heels and soles, children's toys, caulking compounds, sponges, and floor tiles, however the SBR is most massively used in the production of automobile tires ${ }^{1,2}$. According to the International Rubber Study Group, the world production of synthetic rubbers was about 12 million tons in $2009^{3}$.

In this work, SBR was chosen as carbon feedstock for growing nanomaterials because of the high volume of wastes materials containing this rubber. Therefore, the study of SBR can be expanded for tires or other materials that use this copolymer as predominant raw material. The waste rubber materials are thermoset polymers, which cannot be reprocessed like thermoplastic polymers, therefore recycling of these materials requires special techniques that demands high investments ${ }^{4}$. A solution to the disposal of waste rubber products is provided by the pyrolysis or combustion processes. The pyrolysis is a process wherein the material is decomposed using means of temperature with the absence of an oxidized gas, and the combustion is characterized by the addition of the oxidized gases during the process. Past research in the Combustion and Air Pollution Laboratory of Northeastern University showed that SBR products are attractive potential fuels due to their high heating values (29-37 MJ. $\left.\mathrm{kg}^{-1}\right)^{5-7}$, which exceed those of lignite (10-20 MJ. $\mathrm{kg}^{-1}$ ) and bituminous coals $\left(30 \mathrm{MJ} . \mathrm{kg}^{-1}\right)^{8}$. This study proposes a novel technique to co-generate carbon nanomaterials (CNM) during the combustion of SBR, or materials produced from SBR. The reason that SBR is first pyrolyzed and then burned is to be able to generate premixed combustion, upon mixing with oxygen containing gases at the venturi, and thus minimize the production of condensed products of combustion, such as soot ${ }^{7}$. Such products would contaminate the catalyst substrates, which are placed downstream.

Nanotechnology products were responsible for a consumer market of about US\$ 11 trillions in 2010, wherein US\$ 340 billion correspond just to nanomaterials ${ }^{9}$. Nanomaterials consist of structures with at least one dimension in the order of nanometers $\left(1 \times 10^{-9} \mathrm{~m}\right)$. These materials have a wide range of potential applications due to their extraordinary mechanical, thermal and electrical properties ${ }^{10,11}$. To generate carbon nanomaterials carbon bearing gases are needed at an elevated temperature environment. Such gases can be generated by high temperature pyrolysis and/or combustion of hydrocarbon-based feedstocks ${ }^{12}$. In prior work, it was found that carbon bearing gases can be provided from other types of solid waste fuels, such as plastics ${ }^{13}$ and biomass ${ }^{14}$. It will be shown herein that SBR-based products can be used as feedstock to generated nanomaterials.

\section{Materials and Methods}

\subsection{Materials}

Small pellets of SBR with average dimensions of about $2 \mathrm{~mm}$ were used as carbon feedstock for the nanomaterials growth. The physical and chemical properties of the used SBR pellets are shown in Table 1. A ceramic boat was used to insert batches SBR samples of $1 \mathrm{~g}$ in the furnace. 
Table 1. Physical properties and chemical composition of SBR used in the work.

\begin{tabular}{cccccccccc}
\hline $\begin{array}{c}\text { Particle size } \\
(\mu \mathrm{m})\end{array}$ & $\begin{array}{c}\text { Fixed carbon } \\
(\%)\end{array}$ & $\begin{array}{c}\text { Volatiles } \\
(\%)\end{array}$ & $\begin{array}{c}\text { Ash } \\
(\%)\end{array}$ & $\begin{array}{c}\mathrm{C} \\
(\%)\end{array}$ & $\begin{array}{c}\mathrm{H}_{2} \\
(\%)\end{array}$ & $\begin{array}{c}\mathrm{S} \\
(\%)\end{array}$ & $\begin{array}{c}\mathrm{N}_{2} \\
(\%)\end{array}$ & $\begin{array}{c}\mathrm{O}_{2} \\
(\%)\end{array}$ & $\begin{array}{c}\text { Heating value } \\
\left(\mathrm{MJ}^{2} \mathrm{~kg}^{-1}\right)\end{array}$ \\
\hline $180-212$ & 21.7 & 52.3 & 26.0 & 60.9 & 5.3 & 2.5 & 0.3 & 7.1 & 29 \\
\hline
\end{tabular}

\subsection{Samples preparation}

The laboratory furnace consists of a three-section quartz laminar-flow, electrically heated, muffle furnace. The first section $(37 \mathrm{~mm}$ ID $\times 870 \mathrm{~mm}$ ) is the feedstock pyrolyzer, the second section ( $37 \mathrm{~mm} \mathrm{ID} \times 260 \mathrm{~mm}$ long) is connected to a mixing venturi ( $8 \mathrm{~mm}$ ID), and the third section is the nanomaterials synthesis furnace ( $37 \mathrm{~mm} \mathrm{ID} \times 380 \mathrm{~mm}$ long), the effluent of which is connected to the gases analyzers. A design of the furnace can be seen in the Figure 1.

The ceramic boat with the samples was inserted into the furnace with nitrogen serving as carrying gas at the flowrate of $5 \mathrm{~L} / \mathrm{min}$ ensuring the absence of oxygen; therefore, pyrolytic conditions prevailed in the first stage of the furnace. Several temperatures (in the range of $600-1000{ }^{\circ} \mathrm{C}$ ) were tested in the first section of the furnace in order to decide on the pyrolysis conditions that are most suitable for $\mathrm{CNM}$ growth; a temperature of $1000{ }^{\circ} \mathrm{C}$ was selected because it presented the best relation of burned material. In the venturi, the pyrolysis gases come in intimate contact with jets of a preheated $2 \mathrm{~L} / \mathrm{min}$ flow of an oxygen-nitrogen mixture (oxygen mole fractions of 17 and $19 \%$ were tested). As a result of the blending of the pyrolyzates with the preheated oxidizing gases, ignition occurred and a premixed flame was established at the exit of the venturi. The combustion gases were channeled into the third stage of the apparatus where a catalyst mesh was placed perpendicularly to the flow with a predetermined $\mathrm{CNM}$ synthesis temperature of $1000{ }^{\circ} \mathrm{C}$. In order to prevent any combustion-generated particulate matter (as the premixed flames were transient in nature in these batch combustion experiments) from entering the synthesis chamber and contaminate the catalyst, a barrier filter was placed in the division of the two sections of the apparatus. This filter consists of a honeycomb structure made out of silicon carbide $(\mathrm{SiC})$, and performs with a high filtration efficiency resulting in $97 \%$ retention for submicron particles ${ }^{15}$.

The method for the nanomaterials synthesis used in this work was the catalytic chemical vapor deposition (CCVD). The catalyst substrates consisted of circular pieces (10 mm ID) of a mesh made of stainless steel AISI 304 with chemical composition according to ASTM E2016 specification: $\mathrm{Cr}(18-20.0 \%), \mathrm{Ni}(8-10.5 \%), \mathrm{Mn}$ $(\leq 2.0 \%), \mathrm{Si}(\leq 1.0 \%), \mathrm{N}(\leq 0.1 \%), \mathrm{C}(\leq 0.08 \%), \mathrm{P}(\leq 0.05 \%)$, $\mathrm{S}(\leq 0.03 \%)$, and Fe (balance) $)^{16}$.

The duration of each experiment was about 42-50 seconds; as determined by the time elapsed between the onset and the termination of the evolution of $\mathrm{CO}$ and $\mathrm{CO}_{2}$ in the pyrolysis/combustion effluents. These gases were monitored in real-time with an on-line dual infrared analyzer (California Analytical Instrument, Model 200).

\subsection{Sample characterization}

Upon completion of each experiment, the apparatus was cooled down to $200{ }^{\circ} \mathrm{C}$ under nitrogen before the removing the stainless steel meshes. Morphological analyses of the collected materials were performed using Scanning Electronic Microscopy (SEM) and Transmission Electron Microscopy (TEM). Random sections of the mesh were removed and placed directly on the SEM imaging stage. SEM analysis was conducted on a Hitachi 4800 , using a $3 \mathrm{kV}$ voltage, and a working distance of $8.2 \mathrm{~mm}$. For TEM samples, the meshes were sonicated in a $100 \%$ ethanol solution and the products

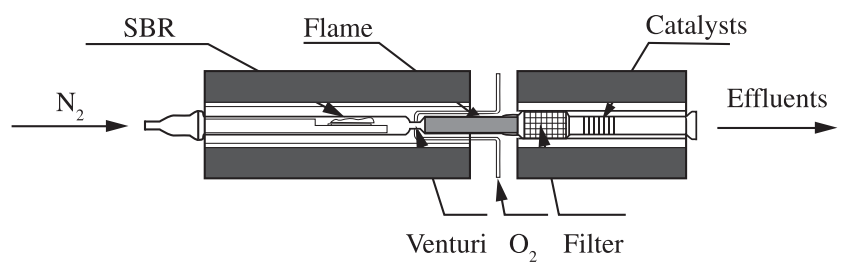

Figure 1. Experimental apparatus consisting of two horizontal furnaces (feedstock pyrolyzer on the left and CNM synthesizer on the right), separated by a mixing venturi where a flame was established.

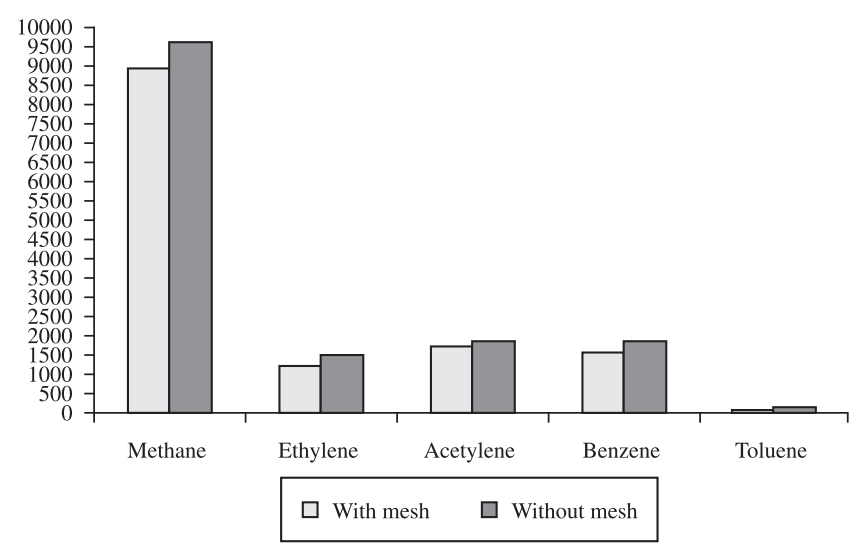

Figure 2. Emissions of the most prominent LHCs (in ppm) detected in the experiments.

were analyzed in a low-magnified TEM (model JEOL 1010, with an accelerating voltage of $70 \mathrm{kV}$ ).

The evaluation of generated effluent gases is important in order to identify the precursors of the CNTs growth. Light hydrocarbon gases (LHCs) generated during the experiments were monitored off-line at the exit of the synthesis furnace. Gases were withdrawn at a rate of $0.5 \mathrm{~mL} / \mathrm{min}$, using syringes mounted on a dual syringe pump. Analysis was performed by gas chromatography (GC), with a HP 6890-series instrument equipped with two parallel columns, one coupled to a flame ionization detector, the other to a thermal conductivity detectors (GC-FID and TCD).

\section{Results and Discussion}

\subsection{Effluents of the pyrolysis/combustion of the SBR feedstock}

The pyrolysis/combustion process of SBR pellets generated several gases, (hydrocarbons, $\mathrm{H}_{2}, \mathrm{CO}$ and $\mathrm{CO}_{2}$ ). The most prominent light hydrocarbon species detected in this work were: methane $\left(\mathrm{CH}_{4}\right)$, acetylene $\left(\mathrm{C}_{2} \mathrm{H}_{2}\right)$, benzene $\left(\mathrm{C}_{6} \mathrm{H}_{6}\right)$, ethylene $\left(\mathrm{C}_{2} \mathrm{H}_{4}\right)$ and toluene $\left(\mathrm{C}_{7} \mathrm{H}_{8}\right)$. Traces of other compounds were also detected, including 1,3-butadiene, propylene, propyne, ethylacetylene and ethylbenzene ${ }^{17}$. Mole fractions of the most prominent LHCs detected in the experiments are shown in Figure 2; data was collected with 


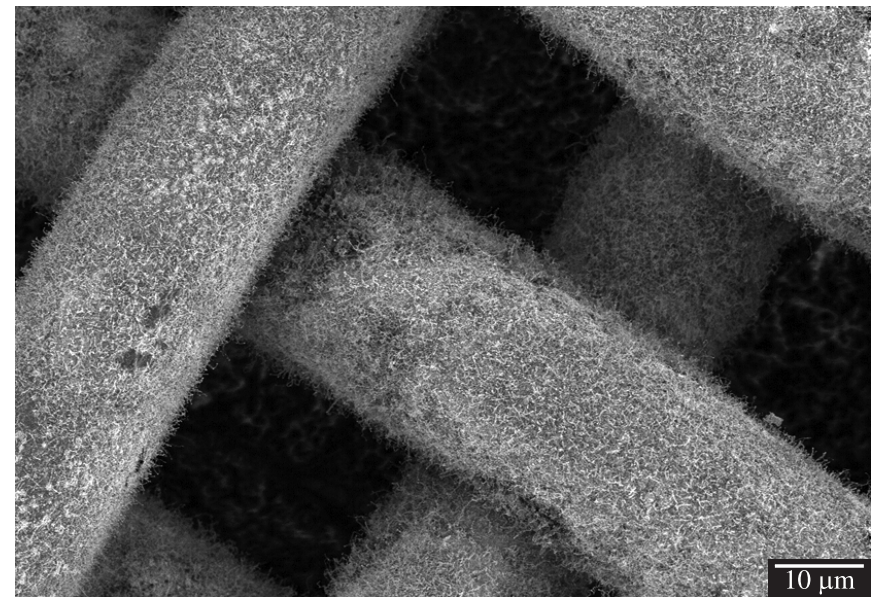

(a)

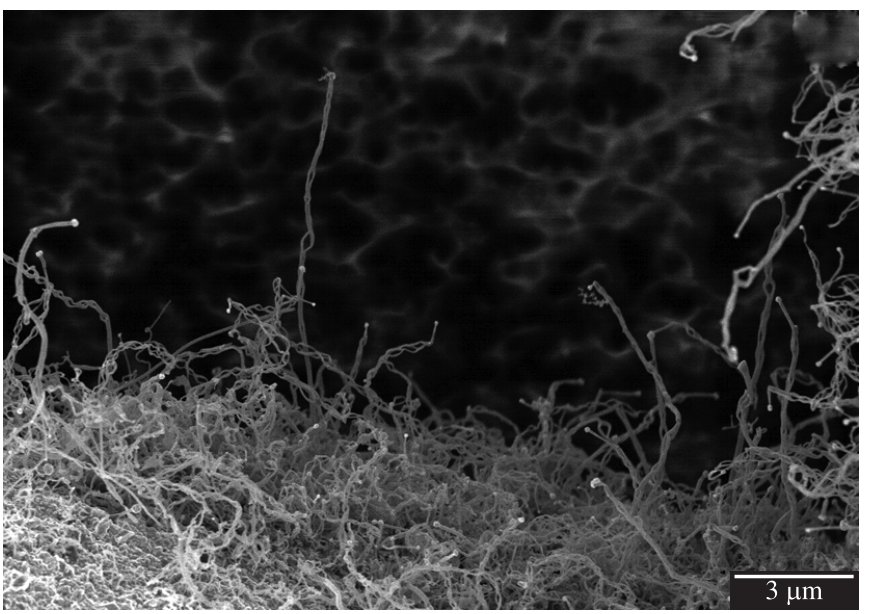

(b)

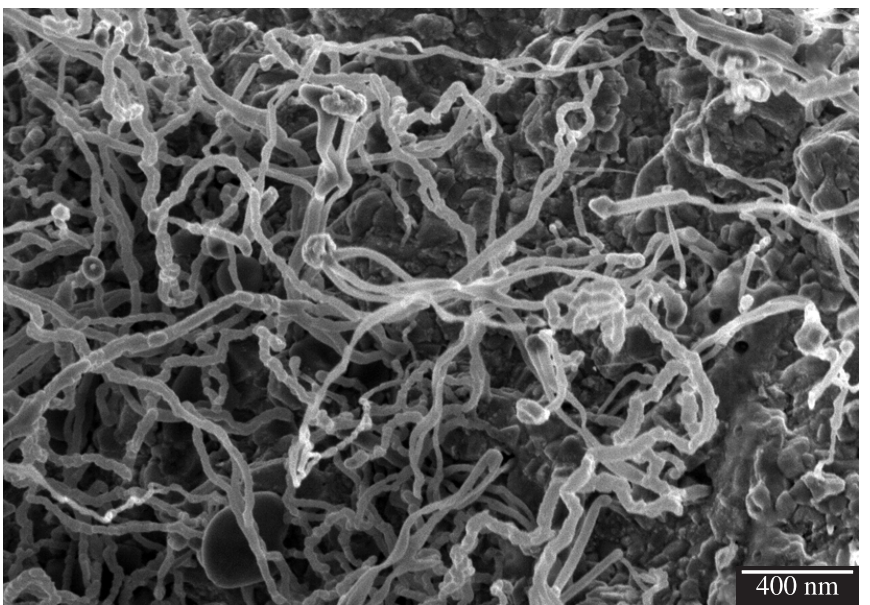

(c)

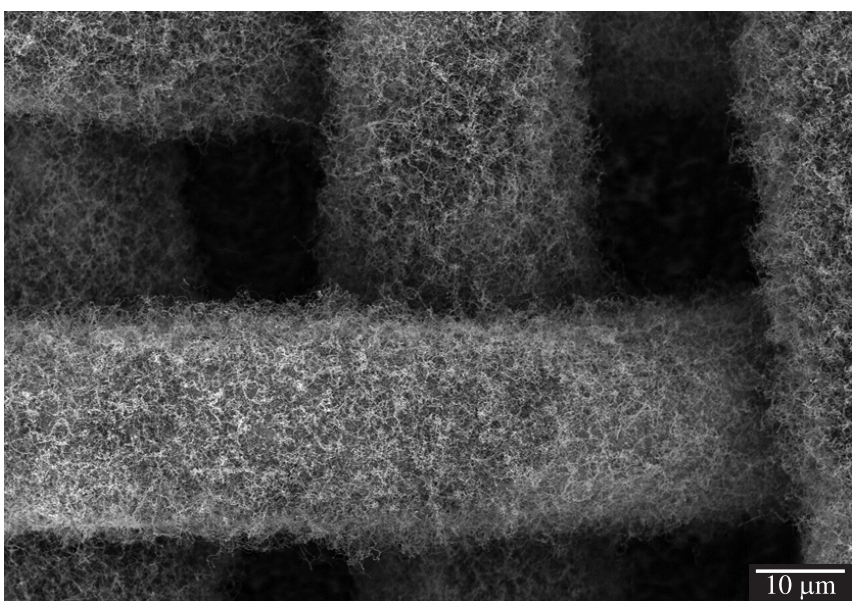

(d)

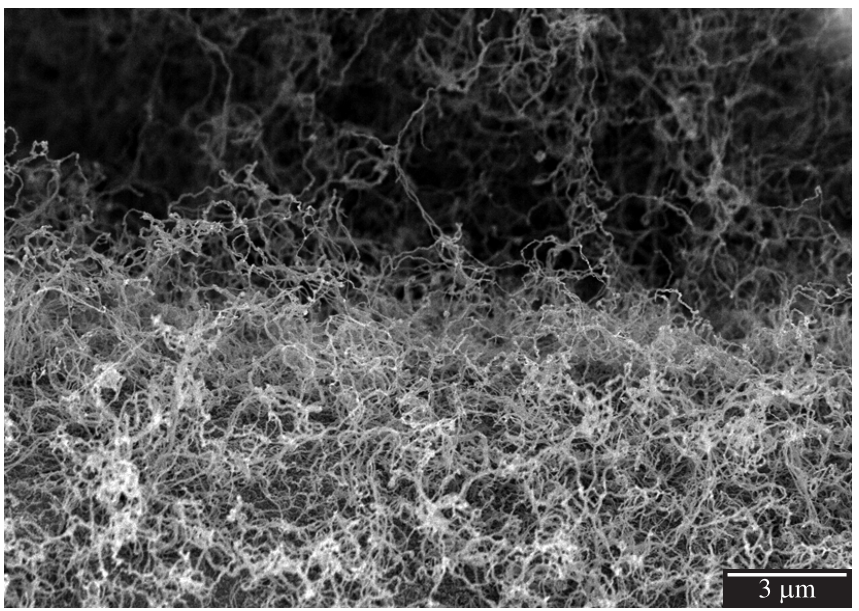

(e)

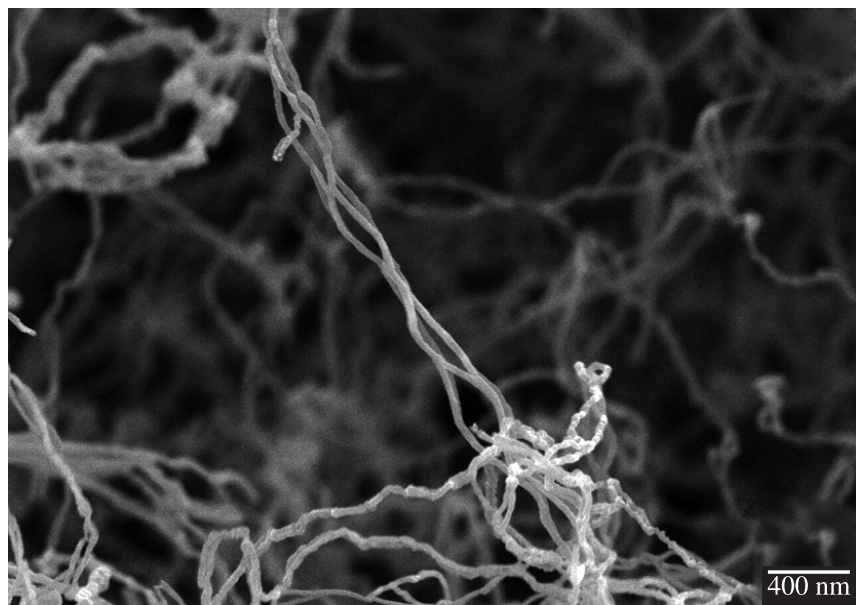

(f)

Figure 3. SEM images of catalyzed materials using SBR using: $17 \%$ of $\mathrm{O}_{2}(\mathrm{a}, \mathrm{b}, \mathrm{c})$ and $19 \%$ of $\mathrm{O}_{2}(\mathrm{~d}, \mathrm{e}, \mathrm{f})$.

and without the catalyst system (the values are listed in parts per million - ppm).

Several prior works have shown that the hydrocarbons can be used as important carbon donors in the production of CNMs using the catalytic CVD method ${ }^{18-24}$. The CCVD process used in this work basically consisted of thermal dehydrogenation reactions whereby a transition metal catalyst was used to "crack" the hydrocarbon gases into carbon and hydrogen ${ }^{12}$. Baker et al. ${ }^{25,26}$ studied the growth of carbon fibers; they describe that the catalytic decomposition of hydrocarbon sources start on the active transition metal surface, wherein they decompose into $\mathrm{C}_{\text {solid }}$ and $\mathrm{H}_{2}$. Thereafter, diffusion of carbon into the metal particles takes place until the solution becomes saturated. The supersaturation of the solution results in precipitation of solid carbon particles in the metal surface, leading to an increase of 


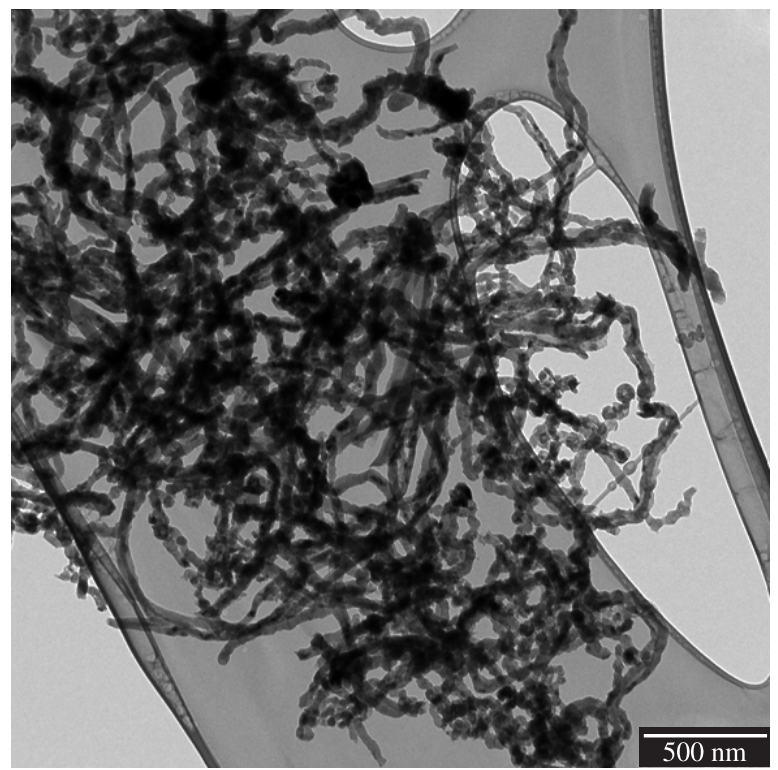

(a)

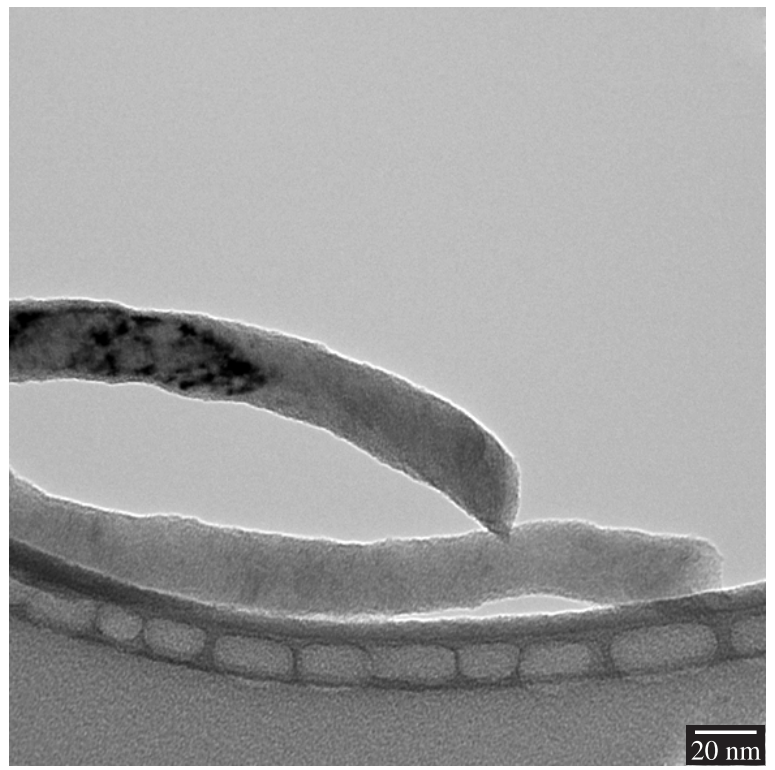

(b)

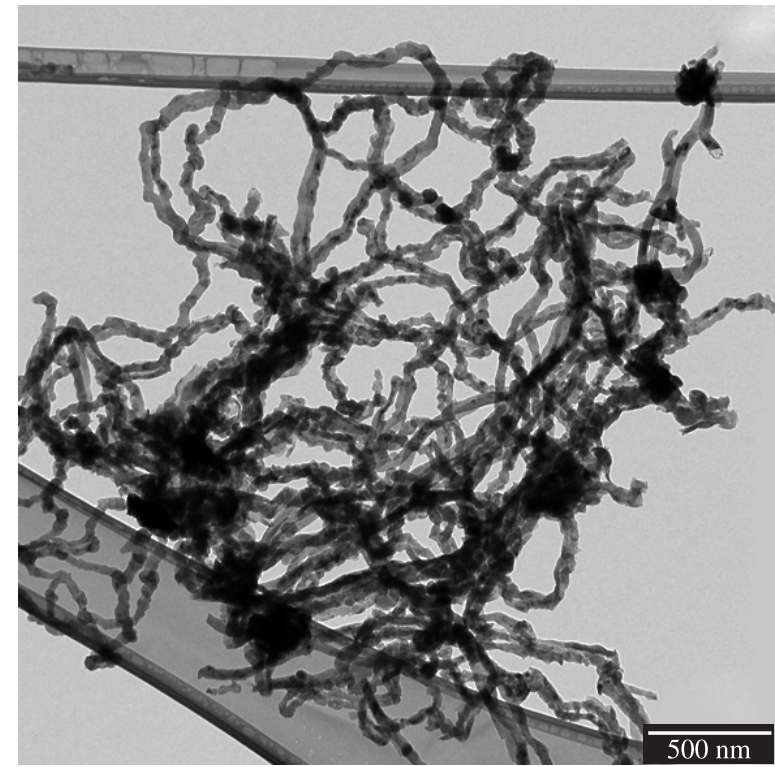

(c)

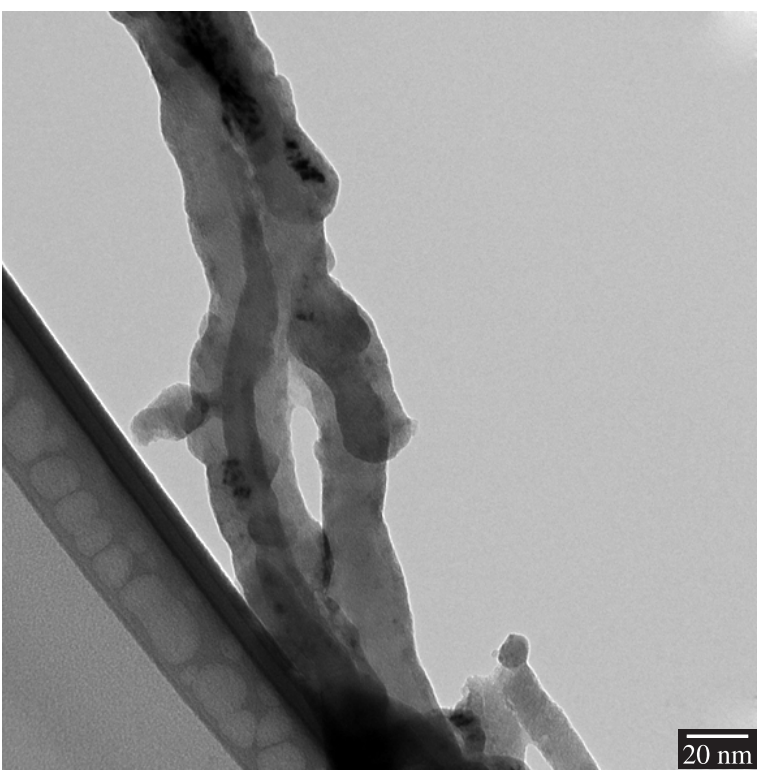

(d)

Figure 4. TEM images of catalyzed materials using SBR using: $17 \%$ of $\mathrm{O}_{2}$ (a and b) and $19 \%$ of $\mathrm{O}_{2}$ (c and d).

the mesh weight. Weight increments of the mesh, $\Delta \mathrm{W}_{\text {mesh }}$, were in the range of $45-50 \mathrm{mg}$. Assuming that CNM synthesis times are equal or shorter than pyrolysis/combustion times, average $\mathrm{CNM}$ growth rates were calculated to be about $1.0 \mathrm{mg} / \mathrm{s}$.

The presence of the catalyst did not have consistent effects on the $\mathrm{CO}$ and $\mathrm{CO}_{2}$ emissions; in some cases a mild increase was observed whereas in some other cases a mild decrease was recorded, typically within experimental error.

A noteworthy trend emerging from the results of Figure 2 is that all detected light hydrocarbon species were partially depleted at the presence of catalytic meshes. This indicates that they are instrumental in the formation process of carbon nanomaterials. Several previous investigations showed that LHCs generated in this work (benzene ${ }^{21,22}$, ethylene ${ }^{23,24}$. methane $^{18}$, and acetylene ${ }^{20}$ ) can be used as carbon feedstock in the production of nanomaterials. For example, when polyethylene was used as carbon feedstock for CNM growth, it was found that major detected pyrolyzates include methane, ethane, ethylene, propane, propylene, acetylene, butane, butadiene, ethylacetylene, benzene and hydrogen ${ }^{13}$, among which ethylene was the predominant. When biomass were used as carbon feedstock, methane $\left(\mathrm{CH}_{4}\right)$, ethylene $\left(\mathrm{C}_{2} \mathrm{H}_{4}\right)$, acetylene $\left(\mathrm{C}_{2} \mathrm{H}_{2}\right)$ and benzene $\left(\mathrm{C}_{6} \mathrm{H}_{6}\right)$ were found to be the highest yield LHCs in the pyrolyzates ${ }^{14}$. Therefore, also as established for the LHCs generated by controlled burned of unserviceable tires ${ }^{27}$, the pyrolysis/combustion of SBR products can be considered an important sources of carbon for growth of CNMs.

\subsection{Microstructural analysis of catalyzed materials}

Scanning Electron Microscopy (SEM) was used to assess the catalyst system success, i.e., to ascertain whether if nanomaterials were formed on the stainless steel meshes. Figure 3 shows SEM images of synthesized materials from SBR; wherein the images 
$\mathrm{a}, \mathrm{b}$ and $\mathrm{c}$ were obtained with $17 \%$ of $\mathrm{O}_{2}\left(83 \% \mathrm{~N}_{2}\right)$ and images d, e and $\mathrm{f}$ with $19 \%$ of $\mathrm{O}_{2}\left(81 \% \mathrm{~N}_{2}\right)$.

SEM images show entangled nanomaterials which cover (not uniformly) the catalyst mesh under all conditions. The images exhibit the catalyst meshes in the background and ramifications of nanomaterials impregnated in the surface. Produced materials showed long fiber forms with lengths of about $30 \mu \mathrm{m}$.

Transmission Electron Microscopy (TEM) was used for additional analysis of the CNM dimensions and, also, to check the structures of the products. TEM images are showed in Figure 4 ( $a$ and $b-17 \%$ of $\mathrm{O}_{2}$, and $\mathrm{c}$ and $\mathrm{d}-19 \%$ of $\mathrm{O}_{2}$ ).

As expected, TEM images showed that the produced cylindrical carbonaceous materials have appear to be either solid or tubular, and may be characterized as nanofibers (CNFs) or carbon nanotubes (CNTs). CNTs were discovered by Iijima $^{28}$ in 1991, and consist of coaxial tubular graphene sheets, with lengths in the order of micrometers and diameters in the order of nanometers. In past years, a variety of synthesis techniques for CNTs have been developed: arc discharge, laser ablation, flame synthesis, and CVD ${ }^{29}$. However, the high cost to produce such materials limits their usage. To reduce the cost of CNTs, it is instrumental to reduce the expenses associated with the procurement of raw-materials and to reduce the production expenses. By using waste rubber products as feedstock for CNT growth, the cost of raw-material can be minimized.

Figure 4 shows the formation of long fibers and some impurities in the background. Outer diameters of the formed materials were in the range of 30-100 nm. Produced materials showed tiny black points, which are metallic particles that were incorporated into the nanotubes during the catalyst process, which was confirmed by EDX measurements. Some impurities are expected in materials produced by catalytic synthesis, thus purification processes are generally used to reduce the presence of undesired components ${ }^{30}$.

\section{Conclusion}

This study demonstrated that a high density of entangled nanomaterials, with outer diameters of 30-100 nm and lengths of about $30 \mu \mathrm{m}$, could be generated from the pyrolysis/premixedcombustion products of SBR on the catalyst meshes. Produced carbon nanomaterials were of cylindrical forms some of which were tubular. They were characterized as nanofibers/nanotubes. Therefore, the use of SBR as feedstock for CNM growth was satisfactory and it may be considered to be an interesting field for future investments due to the high volume of wastes produced from SBR.

\section{Acknowledgements}

The authors would like to thank the CNPQ-Brazil for financing the period of the D.Sc. Joner Alves at Northeastern University (USA). The support provided by CAPES (Grant: 04/CII-2008 - Rede Nanobiotec-Brasil) is also greatly appreciated.

\section{References}

1. Massarotto M, Crespo JS, Zattera AJ and Zeni M. Characterization of Ground SBR Scraps from Shoe Industry. Materials Research. 2008; 11(1):81-84. http://dx.doi.org/10.1590/S1516-14392008000100015

2. Trezza MA and Scian AN. Scrap Tire Ashes in Portland Cement Production. Materials Research. 2009; 12(4):489-494. http://dx.doi. org/10.1590/S1516-14392009000400019

3. Internacional Rubber Study Group. Available from: <www.rubberstudy. com>. Access in: 06/23/2010.

4. Murugan S, Ramaswamy MC and Nagarajan G. The use of tyre pyrolysis oil in diesel engines. Waste Management. 2008; 28(12):2743-2749. PMid:18499428. http://dx.doi.org/10.1016/j.wasman.2008.03.007
5. Levendis YA, Atal A, Carlson J, Dunayevskiy Y and Vouros P. Comparative Study on the Combustion and Emissions of Waste Tire Crumb and Pulverized Coal. Environmental Science \& Technology. 1996; 30(9):2742-2754. http://dx.doi.org/10.1021/es950910u

6. Caponero J, Tenorio JAS, Levendis YA and Carlson J. Emissions from batch combustion of waste tire chips: The afterburner effect. Energy \& Fuels. 2003; 17:225-239. http://dx.doi.org/10.1021/ef0201331

7. Caponero J, Tenorio JAS, Levendis YA and Carlson J. Emissions from batch combustion of waste tire chips: The pyrolysis effect. Combustion science and technology. 2005; 177(2):347-381. http://dx.doi. org/10.1080/00102200590900516

8. Wang L, Hanna MA, Weller CL and Jones DD. Technical and economical analyses of combined heat and power generation from distillers grains and corn stover in ethanol plants. Energ Convers Manage. 2009; 50(7):1704-13. http://dx.doi.org/10.1016/j.enconman.2009.03.025

9. Pitkethly MJ. Nanoparticles as building blocks. Nano Today. 2003; $36: 36-42$

10. Tessonnier JP, Rosenthal D, Hansen TW, Hess C, Schuster ME, Blume R et al. Analysis of the structure and chemical properties of some commercial carbon nanostructures. Carbon. 2009; 47:1779-98. http://dx.doi.org/10.1016/j.carbon.2009.02.032

11. Ávila AF and Lacerda GSR. Molecular Mechanics Applied to SingleWalled Carbon Nanotubes. Materials Research. 2008; 11(3):325-333. http://dx.doi.org/10.1590/S1516-14392008000300016

12. See $\mathrm{CH}$ and Harris AT. A review of carbon nanotube synthesis via fluidized-bed chemical vapor deposition. Industrial \& Engineering Chemistry Research. 2007; 46(4):997-1012. http://dx.doi.org/10.1021/ ie 060955 b

13. Zhuo C, Hall B, Richter H and Levendis YA. Synthesis of carbon nanotubes by the sequential pyrolysis and combustion of polyethylene. Carbon. 2010; 48(14):4024-34. http://dx.doi.org/10.1016/j.carbon.2010.07.007

14. Alves JO, Zhuo C, Levendis YA and Tenório JAS. Catalytic conversion of wastes from the bioethanol production into carbon nanomaterials. Applied Catalysis B: Environmental. 2011; 106(3-4):433-44. http://dx.doi. org/10.1016/j.apcatb.2011.06.001

15. Larsen CA, Levendis YA and Shimato K. Filtration assessment and thermal effects on aerodynamic regeneration in silicon carbide and cordierite particulate filters. SAE; 1999. SAE Technical Paper Series Report no. 1999-01-0466.

16. American Society for Testing and Materials - ASTM. ASTM E2016 - 06: Standard specification for industrial woven wire cloth. West Conshohocken: ASTM International; 2006.

17. Alves JO, Zhuo C, Levendis YA and Tenório JAS. Analysis of light hydrocarbon gases in the pyrolysis and combustion processes of waste tires. In: Proceedings of the 139th TMS Annual Meeting \& Exhibition; 2010; Seattle, USA. Warrendale: EPD Congress; 2010. p. 703-9.

18. Kong J, Cassell AM and Dai H. Chemical vapor deposition of methane for single-walled carbon nanotubes. Chemical Physics Letters. 1998; 292:567-574. http://dx.doi.org/10.1016/S0009-2614(98)00745-3

19. Zhao N, He C, Jiang Z, Li J and Li Y. Fabrication and growth mechanism of carbon nanotubes by catalytic chemical vapor deposition. Materials Letters. 2006; 60(2):159-63. http://dx.doi.org/10.1016/j. matlet.2005.08.009

20. Zhong G, Hofmann S, Yan F, Telg H, Warner JH, Eder D et al. Acetylene: a key growth precursor for single-walled carbon nanotube forests. Journal of Physical Chemistry C. 2009; 113:17321-5. http://dx.doi.org/10.1021/ jp905134b

21. Benito AM, Maniette Y, Munoz E and Martinez MT. Carbon nanotubes production by catalytic pyrolysis of benzene. Carbon. 1998; 36(5):681-3. http://dx.doi.org/10.1016/S0008-6223(98)00039-6

22. Lyu SC, Liu CB, Lee JC, Kang HK, Yang CW and Park CY. High-quality double-walled carbon nanotubes produced by catalytic decomposition of benzene. Chemistry of Materials. 2003; 15:3951-4. http://dx.doi. org $/ 10.1021 / \mathrm{cm} 030309 \mathrm{~s}$ 
23. Khavrus VA, Lemesh NV, Gordeichuk SV, Tripol'skii AI, Ivashchenko TS and Strizhak PE. Catalytic synthesis of carbon nanotubes from ethylene in the presence of water vapor. Theoretical and Experimental Chemistry. 2006; 42(4):234-8. http://dx.doi.org/10.1007/s11237-0060045-0

24. Liao H and Hafner JH. Low-temperature single-wall carbon nanotube synthesis by thermal chemical vapor deposition. Journal of Physical Chemistry B. 2004; 108(22):6941-3. http://dx.doi.org/10.1021/jp048566n

25. Baker RTK, Harris PS, Thomas RB and Waite RJ. Formation of filamentous carbon from iron, cobalt and chromium catalyzed decomposition of acetylene. Journal of Catalysis. 1973; 30(1):86-95. http://dx.doi.org/10.1016/0021-9517(73)90055-9

26. Baker RTK. Catalytic growth of carbon filaments. Carbon. 1989; 27(3):315-23. http://dx.doi.org/10.1016/0008-6223(89)90062-6
27. Alves JO, Zhuo C, Levendis YA and Tenório JAS. Microstructural analysis of nanomaterials synthesized from unserviceable tires. In: Proceedings of the 140th TMS Annual Meeting \& Exhibition; 2011; San Diego, USA. Warrendale: EPD Congress; 2011. p. 253-60.

28. Iijima S. Helical microtubules of graphitic carbon. Nature. 1991; 354:56-8. http://dx.doi.org/10.1038/354056a0

29. Grobert N. Carbon nanotubes - becoming clean. Materials Today. 2007; 10(1-2):28-35. http://dx.doi.org/10.1016/S1369-7021(06)71789-8

30. Lobach AS, Spitsina NG, Terekhov SV and Obraztsova ED. Comparative analysis of various methods of purification of single-walled carbon nanotubes. Physics of the Solid State. 2002; 44(3):475-7. http://dx.doi. org/10.1134/1.1462677 